\title{
The forward edge transference within self-psychology and the activation of inborn capacity through interpretation and internalization
}

\author{
Zelda G. Knight \\ Department of Psychology, University of Johannesburg, Johannesburg, South Africa
}

\begin{abstract}
This paper builds on the ideas of self-psychologists Marian Tolpin and Richard Geist in two ways. Firstly, the idea of using forward edge transference as fostering the promotion of psychological health and well-being. I present two verbatim clinical examples showing the use of forward edge transference, and thus the intersubjective engagement between therapist and patient. I suggest that forward edge transference, rooted in healthy and self-affirming childhood experiences, can lie buried and forgotten. Secondly, using the same two examples, this paper adopts the notion of interpretation as a carrier of selfobject functions and shows how the interpretation of forward edge transferences has the potential to catalyse (forgotten) inborn capacity. Internalization, a part of selfobject function and psychic development, is re-thought of as a process in which an interaction between patient and therapist appears to (re)activate inborn potential/capacity for the patient rather than as something the patient 'takes in' from the other/selfobject.
\end{abstract}

Key words: Forward edge transference; interpretation; selfobject; inborn capacity; health.

\section{Introduction}

Heinz Kohut, whose work formalized the body of analytical literature called 'self-psychology', once noted that it is possible to overlook patients 'forward moves' or 'leading edge transference' which can remobilize often buried but healthy strivings and needs of the self. Marian Tolpin was part of a group in the 1970s that worked closely with Heinz Kohut, whose ground-breaking ideas during those years became core to the perspective now known as self-psychology. Influenced by Kohut, Marian Tolpin (2002) attempted to develop the idea of forward

Correspondence: Zelda G. Knight, Department of Psychology, Faculty of Humanities, University of Johannesburg, Auckland Park Kingsway Campus, 422, C-Ring, Johannesburg, South Africa.

Tel.: 011.559.3635. E-mail: zknight@uj.ac.za

Citation: Knight, Z. G. (2021). The forward edge transference within self-psychology and the activation of inborn capacity through interpretation and internalization. Research in Psychotherapy: Psychopathology, Process and Outcome, 24(3), 241-249. doi: 10.4081/ripppo.2021.550

Received for publication: 17 May 2021

Revision received: 2 August 2021.

Accepted for publication: 7 September 2021.

This work is licensed under a Creative Commons Attribution NonCommercial 4.0 License (CC BY-NC 4.0).

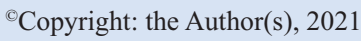

Licensee PAGEPress, Italy

Research in Psychotherapy:

Psychopathology, Process and Outcome 2021; 24:241-249

doi:10.4081/ripppo.2021.550 moves or 'forward edge transference', but her untimely death in 2008 brought an end to this. Tolpin, however, did manage to write about a process with patients that she described as the 'growth transference' or 'forward edge transference'.

According to Tolpin (2002) this forward edge transference encompasses positive and healthy strivings of patients that can sometimes manifest in the encounter between patient and analyst. Tolpin stressed that this focus on the healthy strivings was on direct contrast to the focus on transference repetitions of nuclear childhood pathology, and its later derivatives, or what she termed 'trailing edge' transferences. Due to the greater focus on trailing edge transference, she thought that there was a regrettable tendency to therefore miss 'the subtle hints of bona fide transference that derive their force and momentum from still-viable tendrils of healthy childhood motivations, strivings, expectations, and hopes of getting what is needed now from the forward edge transference to the analyst' (p.167). She described the 'tendrils' of healthy strivings as fragile, and as essentially 'thwarted, stunted, or crushed' (p.167). When there is a focus on trailing edge transferences to the exclusion of forward edge transferences, she claimed, 'we do not support struggling 'tendrils' of health and facilitate their emergence and growth' (p.167). As a consequence, tendrils of health are not fully reactivated in depth and are, she asserted, not accessible to the working-through process. She remarked that it is a slow bit-by-bit process of using healthy tendrils of striving and motivation, often unseen at first, which can be the basis for 'expansion, integration, transformation, and stabilization of healthy aspects of the self into an altered psychic reality' (p.167).

Moreover, Tolpin suggested that 'fragile tendrils of re- 
maining healthy needs and expectations' (p.167) are not always apparent in the therapy. Instead, her work and her clinical examples show that therapists must be "primed to look for them' and to 'tease them out from the trailing edge pathology in which they are usually entwined' (p.167). She emphasized that "tendrils of forward edge strivings have to be disentangled from manifestly pathological mergers, idealizations, grandiosity... rage, envy, depreciation, and, further, from intermediate defences and compromise formations that protect the self the patient has built up and, at the same time, inhibit, restrict, and further compromise normal development' (p.176).

When there is a fostering of the healthy tendencies in the therapy, through the forward edge transference, Tolpin suggested we are likely to "actualize these tendencies and revive the 'urge to complete development' (p.168) indicating that it is possible to remobilize healthy motivations and strivings that were derailed. In her paper, she gave clinical examples of unseen forward edge transferences to demonstrate the need to use the 'total transference' dynamic. She also presented a case where the forward edge was seen as pathology and not as health. Furthermore, she discussed a case where she felt there was evidence for a thwarted attempt at a constructive forward move. In these clinical examples, it was noted that Tolpin maintained that ' a grain of the patient's forward edge of development remained' (p.172) hinting that despite the earlier developmental parental failures, the child's psyche contained healthy strivings that were not contaminated by toxic internalizations. In other words, she showed how she was alerted to conversations within the transference that indicated 'healthy tendrils'. To this end, it is important to understand that there are always these existing tendrils of still-healthy independent initiative and self-assertion entwined with the pathological identifications.

\section{What this paper is about and the structure of the paper}

This paper builds on, and supports, the work of Marian Tolpin (2002) and Richard Geist (2020) in two ways. Firstly, the idea of forward edge transference needs to be given some more attention because there is dearth of clinical examples showing its value in the promotion of psychological health. This paper adds to the growing voices that forward edge transference has something constructive and helpful to offer in the clinical setting in terms of thinking about health and in the advancement of healthy functioning. If we view psychotherapy as a healing process, aspects of the therapeutic process that fosters the forward edge transference becomes quite central to how we understand how healing happens. In this way, using the concept of forward edge transference in the therapy sanctions for the potential for the uncovering of 'tendrils of health'. I present two verbatim clinical examples showing the use of forward edge transference and thus the psycho-dy- namic engagement between therapist and patient. In this context, I suggest that forward edge transference can be rooted in healthy and self-affirming childhood mirroring experiences as well as idealization experiences, but such positive experiences can be buried under trailing edge transference. Secondly, this paper uses the notion of interpretation as a carrier of selfobject ${ }^{1}$ functions (Tolpin, 2002). As such, the paper attempts to show how interpretation of forward edge transferences has the potential to catalyse inborn capacity. To do this, I use the same two clinical vignettes and highlight this kind of therapeutic engagement. Internalization is re-conceptualized as a process in which an interpersonal interaction appears to (re)activate inborn potential/capacity.

As this paper is about forward edge transference, and the idea of interpretation as carrier of selfobject function that can activate inborn capacity, and their related concept of internalization, a succinct description is offered regarding these concepts. This forms the conceptual context for the paper. This lead onto the clinical verbatim examples and a brief re-orientation on the focus of the paper.

\section{The concept of forward edge transference within self-psychology}

It is recognized that forward edge transference is a concept that is similar to positive transference, as first discovered by Freud in his work with patients. Freud (1905) conceived the concept of transference as the patient's repetition or recreation in the relationship with the therapist of actual past events or fantasies, and this was an important way in which the individual could express unconscious material. Freud (1912) differentiated between negative and positive transference. He viewed positive transferences as those which assisted the therapeutic work and those which stalled it as negative transferences. Since then, positive transference has been used widely for many years within psychoanalytic therapies as a way for patients to express positive feelings towards the therapist and thus to explore unconscious transferential feelings that have a positive content that may be a vehicle for change (Benjamin, 2004; Bion, 1962; Diem-Wille, 2004; Falchi \& Nawal, 2009; Gabbard, 2009; Greenson, 1965; Klein, 1952; Ogden, 1986, 2004; Sandler, 1976; Sandler et al.,1992; Schafer, 1977, 1985; Viederman, 2011, 2021). It is thus noted that positive transference and forward edge transference are concepts that are not new. Within self-psychology, however, forward edge transference is understood to have the

\footnotetext{
According to Kohut (1971) the infant's psyche is developed in relation to the mother-object, called 'selfobject'. The quality of the relationship between child and selfobject determines the development of the self-structure. For example, if consistent selfobject responses and attunement to the child's needs are positive, the child's sense of self is built up from this positive experience, and over time, the self becomes confident and assertive.
} 
potential to activate inborn capacities, thus it has an added analysis that is geared towards uncovering potential, while positive transference is the transference of a previously good or positive relationship onto the person of the therapist, without this added level of analysis.

As mentioned, Tolpin's concepts were not developed further because of her death in 2008. Since then, a few authors have used her ideas of forward edge transference. One such author was Linda Marino (2009) who used a case study that she claimed that Marian Tolpin thought of as a good illustration of her ideas about the concept of the forward edge. The paper was a clinical case of a young female patient who entered analysis in a distressed state. Marino pointed out that Tolpin frequently discussed this case, pointing out how pivotal moments in the patient's analysis demonstrated her main point: that clinical momentum and significant intrapsychic change depend on two forms of transference to the analyst - the one that restarts the pathology or 'trailing edge' of development in a 'new edition' of the childhood illness; and the other, revives the 'forward edge of development in a 'new edition' of remaining childhood health. In this article, Marino discussed the analysis and the concepts used, showing their value.

Several years later, Brier and Ornstein (2020), wished to understand how we recognize change and how we know what particular interactional sequences between analyst and analysand have transmutative power. In their work, they used Tolpin's ideas of forward edge transference and trailing edge transference. They tracked verbatim interchanges of disruption-repair cycles between analyst and analysand. In the tracking, they recognized shifts in self-states between trailing edge selfobject mergers and forward edge strivings and transference as well as shifts in the therapeutic relationship. They were able to show what were the interactions that brought about significant healing and repair. These interactions focused on the positive transferences that highlighted the patient's abilities and capacities that were ignored before.

Furthermore, it was thought that Tolpin used the idea of forward edge transference and linked it to interpretation, but it was never quite developed or shown how they related. Tolpin mentioned that interpretation was a carrier of selfobject functions and thus internalization of the positive selfobject function could lead to the strengthening of the sense of self.

Using Tolpin's ideas of interpretation as carrier of selfobject function, Richard Geist (2020) discussed three verbatim interactions with three different patients that exemplified how interpretations catalyse inborn potentials to become sustained abiding psychological capacities (Geist, 2020). This paper emphasized the significance of verbally articulated interpretations as uniquely important because intrinsic to interpretations are selfobject functions. In other words, interpretations are the carriers of selfobject functions, the internalization of which are desirable to concurrently strengthen one's sense of self and to adjust defensive structures (Geist, 2020). He claimed that when an interpretation or genetic reconstruction that carries selfobject functions is experienced as truthful, it can be almost immediately structured building for a patient as long as the patient and therapist share a sense of connectedness and penetrable or porous boundaries (Geist, 2020).

\section{Interpretation as selfobject function and a new perspective on internalization}

It is noted that our understanding of interpretation has changed over the past three decades, and this is reflected in how we now think of interpretation - as only one of the many aspects of healing (Geist, 2020; Ornstein, 2009). Furthermore, we now understand interpretation (both verbal and implicit) as a joint, dyadic, continual action to begin to understand and explain the patient's subjective experience, rather than as a series of statements from analyst to the patient designed to facilitate immediate intrapsychic change through making the unconscious conscious (Geist, 2020). Moreover, there has been a growing tendency to conceptualize interpretation in a broader more encompassing manner - conveying an increasingly deeper consideration of patients through a therapeutic dialogue, or what Ornstein (2009) has called 'speaking in the interpretative mode' (cited in Geist, 2020).

Geist (2020) noted that Tolpin highlighted the importance of verbally articulated interpretations as central because inherent in interpretations are selfobject functions, which she noted were then internalized. The internalization is needed to strengthen one's sense of self. For Geist, this assumption has a number of important clinical implications. To paraphrase, he says: i) It helps us pay more attention to the need for, and significance of, interpretative work in every treatment. It suggests that the disruption/repair cycle, while unavoidable and clearly useful in facilitating transmuting internalizations, is not essential for internalizations to occur. ii) It implies that while feeling understood on a deep level promotes a sense of cohesion, understanding is not so much the carrier of selfobject functions, but rather it accelerates the patient's capacity to be more open to metabolizing interpretations. iii) Finally, in the context of what he has called connectedness (Geist, 2008) interpretations can help or aid in one's sense of self feeling vital, harmonious, and cohesive during the interpretative dialogue (p. 339). In this regard, interpretations that include selfobject functions seem to enable more instant changes because they encourage the integration of split off affects; promote the expansion of permeable boundaries; suggest a sense of relational protectiveness; and raise a sense of affective intimacy between patient and analyst, all of which contribute to the strengthening of one's sense of self (Geist, 2020). More importantly, they catalyse an internalization process that does not rely on 'taking in' or 'taking over functions' from 
the therapist or other. This last point relates to a new perspective on internalization, which is described below.

I am drawing from Geist (2020) to clarify some points of understanding the new perspective on the concept of internalization. This new understanding is used in this paper. According to Geist, most people will understand internalization as the patient taking over, bit by bit, the functions of the selfobject or analyst as selfobject. However, he says internalization has come to be thought of quite differently. It is instead thought of as a process that triggers or activates what is already there, what has always been there - that is inborn capacities or potential that has not yet been fully realized. It is not so much about 'taking in something' from another but that what is already inside the patient is mobilized by the experience of the interaction between the patient and the analyst (the interpretation). If the surrounding environment is supportive, these inborn capacities will emerge:

'For example, a patient who has not felt recognized and seen as competent and valued in a selfenhancing way may experience an interpretation that carries a mirroring selfobject function as building immediate (although initially tentative) self-structure because he is born with the potential capacity for healthy self-esteem. The patient experiences these transactions as corrective emotional experiences that mobilize inborn potential' (Geist, 2020, p.339).

From Geist's point of view, given this reconceptualization of internalization, interpretations are powerful processes, especially if there is an empathic and growth enhancing 'intersubjective connectedness' between patient and therapist, because they can 'catalyse potential enduring capacities that often contradict deeply entrenched feelings about oneself at the very point of transaction between patient and analyst' (p. 339).

\section{Mirroring and idealizing experiences and the ability for the activation of inborn capacity}

In a similar way to what Geist has done, below I present two clinical verbatim examples of forward edge transference and interpretation as a carrier of selfobject functions when such functioning has the potential to catalyse inborn healthy capacity or potential, and thus, healthy psychological ways of relating to self and other. What I have done differently from Geist is to be more direct in showing how forward edge transference is rooted in mirroring and idealization experiences of early childhood, but often these positive and self-affirming experiences are buried or forgotten. In other words, forward edge transference can be embedded in developmentally appropriate needs for mirroring experiences - which Kohut reminded us of is the parental responses and attunement to the child's needs that positively build up the child's self-structure (Kohut, 1971). The childhood developmental needs for mirroring experiences (when the mother or caretaker meets the psychic need of the child to be admired and praised) must be repeated often so that they function to build or form a self-structure of healthy ambitions, selfesteem and assertiveness (Kohut, 1971). The sense of self is bolstered by the mother's mirroring, and is the bedrock of healthy grandiosity (Kohut, 1971). Gradually, the child must 'take in' the mirroring experience of feeling recognized and admired (transmuting internalization). In other words, the childhood need for mirroring experiences of the mother/selfobject stops and fails at some point, (the mother is not perfect but good enough in her attention to the child) and thus cannot always be there. This environmental failure is not a bad experience for it allows the child to learn to do the psychic function or work for himself (give himself the sense of worthiness). However, and I attempt to show this in the clinical examples, these positive experiences can be forgotten and hidden as the child grows up and as negative experiences and miss-attunement become the main source for the development of a poor or weakened sense of self. Forward edge transference can also be rooted in healthy and self-affirming childhood idealization experiences too. Idealization experiences relate to the childhood developmental need to admire (Kohut, 1971). They are the polar opposite of mirroring experiences. The self is thus assumed to be structured as split or bi-polar (mirroring and idealization). Kohut noted that if the parental responses are attuned to the child's needs for idealization of the other, these experiences are transmuted into the capacity for healthy ideals and values.

The main aspect of these developmental experiences in childhood and the parental attunement and empathy is that they are internalized and give rise to the capacity for living a life based on a positive sense of self. In other words, healthy psychological development of the self is thought to be an integration of the two poles of experience, giving rise to health and well-being but within a context of the relational or the other. The other is pivotal in this process. Furthermore, inborn capacity or potential is defined as the innate capacity for self-esteem, a sense of worthiness, healthy ambitions, assertiveness, confidence, the capacity for relational intimacy, tenderness, love, and connection to another without losing a sense of self, healthy ideals and values, as well as the overarching tendency to live life authentically, or from a healthy sense of self without being swayed or damaged and weakened by an external locus of control. As indicated earlier, inborn potential means that it is already there existing within the psyche, and the psyche uses self-enhancing experiences and positive responses of attunement from others that can potentially activate and open up or unlock what is already within but to become realized or actualized. This inborn capacity for health and well-being points to the well-known analytical idea of the psychological environment (environmental mother) as either fostering/en- 
hancing or hindering and de-railing development (Beebe \& Lachmann, 2002; Winnicott, 1965; 1971). If this is the case, the environment can potentially catalyse inborn potential just as it can also catalyse the burying of capacity and the concomitant resultant development of a fragile sense of self, unloved, insecure, ignored, abandoned, weakened by toxic responses or replies from possibly selfabsorbed, immature, narcissistic parents/caretakers.

To work with any kind of transference - forward edge or trailing edge transference (Tolpin, 2002) but to foster growth within the patient, it is imperative that there be an empathic connectedness between patient and therapist (Geist, 2008; 2015; Kohut, 1984). This is not to say that work with only forward edge transference leads to health and a positive self-esteem. Work with trailing edge transference also assists in the development of healthy ambitions and values.

\section{Brief review of the purpose of the paper and the clinical verbatim examples}

The purpose of the paper and the clinical verbatim examples is to give attention to the idea of forward edge transference as it emerges in the intersubjective milieu that makes up the dynamic process of psychotherapy, and to attempt to show its value in the fostering of psychological health and positive self-esteem. In this context, I show that forward edge transference can be rooted in healthy, self-affirming childhood mirroring experiences and idealization experiences, which can be forgotten or buried. The second purpose of the clinical verbatim examples is to show interpretation as a carrier of selfobject functions, and thus, the interpretation of forward edge transferences has the potential to catalyse or reactivate inborn capacity. There is a short comment after each vignette is presented.

\section{First vignette: Johanna}

$J_{\text {Johanna }}^{2}$, a young woman of 25 , has been in therapy for about a year when this interaction occurs.

Johanna: I am finding that I am speaking my mind more, being honest with people, not keeping things back because they may feel hurt. I am not unkind, but I speak my mind.

Therapist: Ah that sounds like something new. Would you like to share something about it with me?

Johanna: Sure. It feels really good. You know I have

\footnotetext{
Every effort has been made to be faithful to the experience of the patients in using the verbatim transcripts. Patients have given permission for the transcripts to be shown, although there have been some modifications to prevent patient identity being revealed. At the time of writing, none of the patients were in therapy with me, having long since terminated. The implication is that there was no contamination or distraction of the therapy process as a result of this research. Both names and context of the two patients have been changed to protect their real identities.
}

sometimes battled to speak my mind and say what I feel. But I think I first spoke my mind here with you. I think I feel you can handle stuff I say so I started to not hold back with you.

Therapist: If I am understanding you correctly, you feel you can maybe trust me not to be hurt by what you say. Something about us being together seems positive for you in that you can speak your mind with me.

Johanna: Yes, exactly. I think I am beginning to trust you too. Being here with you I speak my mind. It feels good. And when I speak my mind, something happens inside.

Therapist: If I hear you correctly, and correct me if I am wrong, something happens inside that makes you feel differently about yourself because you are learning to speak your mind and not be afraid to express yourself.

Johanna: Yes, exactly. I start to feel brave. I start to feel that I can stand my own ground. That what I have to say is actually fine. Not that I am always right or want to win the argument but that I have a voice, and my voice can be added to conversations. I feel I can participate.

Therapist: These experiences you describe sounds very self-affirming and constructive for you. This newfound voice seems to make you feel more confident about yourself, and that you can be a part of the conversations. This is something new, right? I haven't heard this before. This speaking your mind experience is changing you inside. It is something you have felt here with me, and speaking your mind makes you feel different inside, perhaps more self-assured?

Johanna: Exactly. It means that I can add my voice, add my opinions to the conversations. When I speak my mind, when I say what I truly think, I get the sense of being respected. It feels good. I get this sense with you too. I feel you respect me too.

Therapist: From what you tell me, and if I hear you correctly, you experience me as being respectful to you. Your experience is that you can speak your mind here. I wonder if being respected has always been something important to you and to how you view yourself? Maybe with me, with us here, this feeling of being respected could be linked to the new experience of being able to speak your mind?

Johanna: Yes, I think this is the case. They are mixed together. I feel I can speak my mind, and then, this makes me feel respected. But I think I feel respected within, or that I am worthy, and this new sense of self fosters within me an ability to speak my mind, to feel confident. I feel energized and alive. I feel good inside about myself.

Therapist: That feeling of being worthy is something new as well. You have not said anything like this before. It all sounds like a positive experience.

Johanna: Yes, it is. I use this confidence when I walk into a room now. I did not before. Now I think that this feeling of being alive is familiar.

Therapist: Tell me a bit more about it being familiar. Sounds important.

Johanna: Yes. It started with therapy and you and me, 
but I remember this feeling of being confident and alive, of speaking my mind and being respected. I remember when I was a young child. I was young and my mother was outside in the garden, doing the garden and plants, and I was pretending to be a warrior princess and standing up on a high pile of leaves, calling out to my pretend gods and goddesses, and commanding them to bring the sunshine - it must have been a cloudy day. My mother was standing close by, and she called out to me and said, 'Johanna, you are a powerful little person, and you can say anything and speak your mind. You have a strong voice, and all the gods will hear you'. Well, something like that. I felt my little chest grow large and I can remember that feeling of her being proud of me, admiring me. it was a good feeling.

Therapist: What an amazing experience for you. Your mother recognized your strong voice and power, and she told you that you could speak your mind. I wonder, if somehow, over the years, that experience of being affirmed and valued like that has been forgotten and lost? You mentioned it was familiar to you but have not spoken about it before.

Johanna: Yes, I have forgotten it. All the years have passed, and I lost my voice. I lost that ability to feel confident and speak my mind. But now I have found my voice.

Therapist: I am so glad for you that you have found your voice. This sounds like an encouraging discovery you have made about yourself. I am so impressed that you have a new sense of self that feels to you to be valued and respected. I am also glad you have spoken about this experience with me. In fact, what I am picking up is this powerful little girl who could command the gods and goddesses and speak her mind. Now I have a sense that she is coming back again. She is being called.

Johanna: Yes, I think I feel that I am reclaiming that powerful little girl, that voice she had that was lost.

\section{Comment on the vignette with Johanna}

In this session, Johanna finds a lost part of herself and an inborn capacity for self-confidence and a sense of worthiness. Her mother was the first mirroring experience that initiated this development and self-structure, but it has lost over the years. In my experience, I find this forgotten yet positive experience a common trend. When working with the forward edge transference, this lost capacity has the potential to emerge in the transference. Johanna tells me that she is experiencing something new which is her (lost) ability to speak her mind. It starts in the therapy, and thus becomes part of the transference. Because it has a tendril of health, it is a forward edge transference. Johanna tells me she does not feel I will be hurt (damaged by her new ways) and I reflect back to her that this is something good that is happening between us. In this way, I am the selfobject that mirrors something good that is beginning. My interpretation as selfobject function is to highlight that she can trust me and not be hurt by I say. But I push this fur- ther to pay attention to the intersubjective interaction which is to tell her that something about us being together seems positive. This draws out the forward edge transference and makes it more concretized and explicit. Johanna affirms this experience of the transference. As the forward edge transference develops, she tells me something about her inner world that it is new - she says, 'when I speak my mind something happens inside'. This is an important therapeutic moment. She recognizes this shift within the transference, and my interpretation at this juncture as selfobject function is internalized. This is evident when she says, 'I start to feel brave. I start to feel that I can stand my own ground'. This self-affirming experience is an inborn potential that has been there all along. I say, 'This experience you describe sounds very self-affirming and constructive for you' which reinforces something she is already feeling about herself. Something she is beginning to remember and get in touch with. This speaking her mind is changing her. In my further interpretation in which I reflect that what I hear is that she experiences me as being respectful, I suggest that 'being respected has always been something important', and I bring our intersubjective to the fore when I say to her, 'Maybe with me, with us here, this feeling of being respected could be linked to the new experience of being able to speak your mind'. This opens up Johanna and she begins to speak more about this, again the mirroring experience and the forward edge transference dynamic heightens this. This is confirmed when she says, 'I feel I can speak my mind... I feel respected... that I am worthy'. I again re-affirm this positive experience which results in her feeling 'alive' which is a familiar feeling. It is this familiarity that I pay attention to because it indicates something that has been experienced before. This invitation for her to speak more about this familiarity gives way to her childhood memory of being with her mother in the garden. It is a life-affirming experience for Johanna, and she finds in this memory a strong and powerful individual who can speak her mind. My response is to ask if maybe, 'over the years, that experience of being affirmed and valued like that has been forgotten and lost?' Johanna tells me this is the case, but she also internalizes something about the experience, which is that she had lost her voice, and 'lost that ability to feel confident'. At the end of the session, Johanna tells me that she is 'reclaiming that powerful little girl'. The implication is that this inborn capacity for self-confidence and a sense of worthiness is gradually coming to the forefront and bringing a 'voice that was once lost'.

The session with Johanna shows that the forward edge transference has something constructive and useful to offer in the clinical setting in terms of conceptualizing therapy as the potential to foster inborn capacity. The forward edge transference is a therapeutic action that allows for a focus on 'tendrils of health' which can, in turn, bring about the realization of potential, such as confidence. Furthermore, this case shows that forward edge transference 
can be rooted in healthy and self-affirming childhood mirroring experiences as well as idealization experiences. My interpretation of her experiences of therapy and the transference dynamic, functions to activate the inborn capacity.

\section{Second vignette: Thabo}

Thabo, 28, a Zulu African man fell in love with a woman from another African culture. They got married after a short courtship, but the two families were not always supportive of the union. When their first child was born, his wife wanted to go back to work soon after, but the families tried to stop her. Thabo was supportive of his wife, and he arranged for home care and a nanny for the baby, much to his parents' disapproval. This kind of family set up, with its disapproval and lack of support, mirrored so much of what Thabo had experienced in his childhood - a strong resistance from family and others for his own choices and decisions. Despite this, he managed to forge his own pathway in life, but it was not easy for him.

Thabo: I am always thinking what will my parents say before I do anything. It is annoying. But I do go ahead and do what I think is best for me, or for my family.

Therapist: This parental approval has dogged you for some time, but what I hear is that despite their views and opinions, you seem to go ahead with things anyway. Have I understood you or missed something?

Thabo: Yes, you get it. I do as I think I need to feel that I am making a life for myself which is based on my own values and choices. It is a choice, for example, that I am in therapy with you. It is a decision I have taken for myself - to give myself this opportunity to examine me, it is a me-project, to explore my life, my world.

Therapist: Correct me if I am wrong but I feel a 'but' coming on.

Thabo: Yes, exactly, there is a 'but'. You know me well. I think it is about approval and disapproval. When I feel I do things for myself I feel their eyes on me, their disapproval but when I do things based on my own values, I feel like I am living an authentic life.

Therapist: Okay so what I hear is that when you do what is based on your values, you feel authentic.

Thabo: Yes. For example, when I was a child, I remember my grandfather telling me to be true to myself, to find my own way, to not live in the shadow of another, and to speak about things that matter to me. When I recall his words to me, it reminds me that I am doing this, and this is what it means to be living an authentic life.

Therapist: It sounds like your grandfather gave you some important advice that became important to you later on in your life, like a guide or map as to how to navigate your world. Do I have it right or am I not understanding fully?

Thabo: Yes, exactly, it is a map of some kind, but I sometimes struggle still to separate out the "what will my parents say before I do anything' and I find it is tough too because their voices are loud. But I somehow manage. I say what I want in the end. Like I do here with you.

Therapist: I am glad you say what you want with me. That is good to know. Now I might have it wrong but let me say it anyway and you can agree or not - I wonder if maybe you think about me in the same way as you do with your grandfather?

Thabo: Yes. I get the sense that you are also wanting me to find my own way, to make my own decisions and choices, and to be true to myself.

Therapist: So you experience me as someone, like your grandfather, wanting you to find for yourself what is authentic and real. So I remind you a bit of your grandfather.

Thabo: Yes, you have it right. You give me space in this room to tell you that I am also okay, doing well, living from my values and living an authentic life. I get a sense of something positive going on here. In a way, you sometimes frame things in a way that makes me think about how I can change things for the better, what I can do rather than what I cannot do.

Therapist: If I get what you are saying and correct me if I am wrong, you experience me in a positive way, like you once experienced your grandfather. If this is the case, it sounds very positive and growth affirming.

Thabo: Yes. Exactly. So, in here I feel positive about us. I feel alive then. I feel positive about me, and about us.

Therapist: Okay so if I am understanding you correctly, the sense you get of something positive going on here is perhaps about a sense of feeling positive about yourself. Is this what you are saying?

Thabo: Yes, and each time I am here, as we speak about my life and experiences, I am remembering that it is also about what I can do and not about what I cannot do.

Therapist: This sense you have, if I hear your correctly, of 'remembering that it is also about what I can do and not about what I cannot do' seems to be quite core to some of your thoughts about yourself. You focus more on the 'can' part rather than the 'cannot' part. What goes on for you when this happens?

Thabo: I feel alive. Simply alive. Pumped up and ready to face anything. I can do rather than I cannot do. I feel plugged in. My battery is charged, and I am ready. I get this from us being together. It reminds me of my conversation with my grandfather. When I hear the loud, disapproving voices of my parents, I also hear inside my head the voices of us both here, speaking about something positive going on, about feeling alive and positive. This is what takes me forward and away from the bossy and overpowering parents who are always disappointed and disapproving.

Therapist: And what of the 'what will my parents say before I do anything' - what happens to this?

Thabo: I can release it, mostly, most of the time. It is getting easier. I let it go. I remember what we talk about here is both positive and enriching, as well as what we talk about that is sad and bad. I have cried here. But I have 
also found something here that brings me back to being true to myself.

\section{Comment on the vignette with Thabo}

In this session, Thabo shared his sense of disapproval from his family, but there is a grain of health when he tells me he carries on doing what he thinks is best. This capacity to forge ahead despite such lack of support indicated to me that we were on the edge of a forward edge transference, meaning that I could 'hear' another voice that was one of inner strength. I worked with what he presented to me, and he replied at one point, 'I do as I think I need to feel that I am making a life for myself which is based on my own values and choices'. My response was quite bland and did not do much except to reflect his experience, but what later emerged was his memory of his grandfather. The grandfather presented a positive mirroring experience for the young Thabo, in that Thabo found his advice to be helpful. He said, 'I remember my grandfather telling me to be true to myself, to find my own way, to not live in the shadow of another, and to speak about things that matter to me. When I recall his words to me, it reminds me that I am doing this, and this is what it means to be living an authentic life'. In this context, Thabo was able to identify what it was that made him feel he could live an authentic life despite the loud voices of parental disappointment. This positive affirmation of the sense of self is built on the early childhood mirroring experience of the grandfather. The essence of this central figure in his childhood world was internalized as fundamentally something positive. The transference of this experience in the therapy was made when he said that I was like his grandfather. The implication is that our intersubjective engagement resulted in his feeling like something was also affirming for him with us. While he mentioned his continued struggles to ignore the loud voices of his parents, he seemed to also be in touch with the capacity to manage despite this. The interpretation that followed this part of the session was to heighten the link between the grandfather and me in terms of an experience of living an authentic life despite the resistance from family. For example, I said, 'I am glad you say what you want with me. That is good to know. Now I might have it wrong but let me say it anyway and you can agree or not - I wonder if maybe you think about me in the same way as you do with your grandfather?'. I am praising him as well as drawing the links, which acts like a selfobject function as well as an echo of the earlier transference with the grandfather. This therapeutic dynamic results in his understanding that I am wanting the same for him as the grandfather wanted. His reply affirms this connection when he says, 'I get the sense that you are also wanting me to find my own way, to make my own decisions and choices, and to be true to myself'. The therapy process has become one of a forward edge transference, and he tells me that I give him space, and that I notice that he is doing well in living from his own values. This is a mirroring experience within the forward edge transference, and it results in his sense that 'something positive' is happening, and that in our relating together, he is able to think about how he "can change things for the better'. Thabo is tapping into something important here about his own ability to change, which is, for him, positive and affirming. He tells me in response to my comment that that, 'I feel positive about us. I feel alive then. I feel positive about me, and about us'. I again bring this interaction to the fore because I am paying attention to how he experiences us and how it is a forward edge transference. I say, 'I am understanding you correctly, the sense you get of something positive going on here is perhaps about a sense of feeling positive about yourself. Is this what you are saying?' Thabo affirms this. This is where there is a shift in the process to something I think is about an internalization of the selfobject function. He says, 'I am remembering that it is also about what I can do and not about what I cannot do'. This experience is the overarching sense of self confidence that he seemed to sometimes battle to keep with a background of parental disappointment. From this point onwards, he uses what I give as an interpretation to highlight something he has gradually come to recognize within. He feels alive. This aliveness is the root of his ability to 'face anything'. It is a positive forward edge transference when he tells me, 'I remember what we talk about here is both positive and enriching, as well as what we talk about that is sad and bad. I have cried here. But I have also found something here that brings me back to being true to myself'. The interaction between us again draws out further aspects of the forward edge transference. This positive transference was a tendril of healthy motivation. Throughout the session, my interpretations (as selfobject function) of the forward edge transference and thus heightening the tendrils of health, catalysed inborn potential to live an authentic life based on a true self.

\section{Conclusions}

This paper sought to builds on the ideas of Marian Tolpin (2002) and Richard Geist (2020). Using two clinical examples of the forward edge transference, I have shown its usefulness in fostering tendrils of health. In both clinical examples, working with the forward edge transference has resulted in the emergence of something positive that can add to the self-structure and become something affirming and constructive. I have attempted to show that forward edge transference can originate in childhood mirroring and idealization experiences, which are sometimes buried beneath negative and destabilizing experiences that hid what once was something good and healthy. I have used the verbatim sessions to attempt to show interpretation as a carrier of selfobject that has the potential to catalyse inborn capacity. To do this, Johanna found her voice which catalysed a sense of self confi- 
dence, and Thabo found he could live his life authentically and be true to himself. Our interaction together within the forward edge transference appeared to (re)activate inborn potential/capacity.

\section{References}

Beebe, B., \& Lachmann, F. (2002). Infant research and adult treatment: Co-constructing interactions. Hillsdale, NJ: Analytic Press.

Benjamin, J. (2004). Beyond doer and done-to: an intersubjective view of thirdness. Psychoanalytic Quarterly, 73, 5-46.

Bion, W. R. (1962). A theory of thinking. In Second thoughts (pp. 110-9). London: Heinemann.

Brier, R. \& Ornstein, A. (2020). Tracking changes in the disruption/repair sequences: Important aspects of clinical work. Psychoanalysis, Self and Context, 15, 1-9. doi:10.1080/ 24720038.2020 .1849222$.

Diem-Wille, G. (2004). Using the concept of the 'total situation' in the analysis of a borderline adolescent'. Journal of Child Psychotherapy, 30, 308-329.

Falchi, V. \& Nawal, R. (2009). Transference, Countertransference and interpretation: The current debate. European Journal of Clinical Hypnosis, 9(1), 11-18.

Freud, S. (1905). Fragment of an analysis of a case of hysteria. In Standard edition of the complete psychological works of Sigmund Freud, Vol. 7. London, UK: Hogarth Press.

Freud, S. (1912). The dynamics of transference. In Standard edition of the complete psychological works of Sigmund Freud, Vol 14. London, UK: Hogarth Press.

Gabbard, G. (2009). Transference and countertransference: developments in the treatment of narcissistic personality disorder. Psychiatric Annals, 39, 129-36.

Geist, R. A. (2008). Connectedness, permeable boundaries, and the development of the self: Therapeutic implications'. International Journal of Psychoanalytic Self Psychology, 3(2), 129-152. doi:10.1080/15551020801922971.

Geist, R. A. (2015). Conversations with Paul. International Journal of Psychoanalytic Self Psychology, 10(2), 91-106. doi:10.1080/15551024.2015.1005795.

Greenson, R. (1965). The working alliance and the transference neuroses. Psychoanalysis Quarterly, 34, 155-81.

Klein, M. (1952). The origin of transference. In The writings of
Melanie Klein, vol. 3, London, UK: Hogarth Press.

Kohut, H. (1971). The analysis of the self. New York, NY: International Universities Press.

Kohut, H. (1984). How does analysis cure? Chicago, IL: University of Chicago Press.

Marino, L. (2009). A case exemplifying the forward edge. International Journal of Psychoanalytic Self Psychology, 4, 57-73. doi: 10.1080/15551020902958858

Ogden, T. (1986). The matrix of the mind. Northvale, NJ: Aronson.

Ogden, T. (2004). The analytic third: implications for psychoanalytic theory and technique. Psychoanalytic Quarterly, 73, 167-96.

Ornstein, A. (2009). Do words still matter? Further comments on the interpretive process and the theory of change. International Journal of Psychoanalytic Self Psychology, 4(4), 466-484. doi:10.1080/15551020903185824.

Sandler, J. (1976). Countertransference and role-responsiveness. International Review Psychoanalysis, 3, 43-47.

Sandler, J, Dare, C., \& Holder, A. (1992). The patient and the analyst: the basis of the psychoanalytic process. London, UK: Karnac Books.

Schafer, R. (1985). The interpretation of psychic reality, developmental influences, and unconscious communication. Journal of the American Psychoanalytic Association, 33, 537-554.

Schafer, R. (1977). The interpretation of transference and the condition of loving. Journal of the American Psychoanalytic Association, 25, 335-62.

Tolpin, M. (2002). Doing psychoanalysis of normal development: Forward edge transferences. In W. Coburn (Ed.), Progress in self psychology, Vol. 18 (pp. 167-189). Hillsdale, NJ: The Analytic Press.

Viederman, M. (2011). The induction of noninterpreted benevolent transference as a vehicle for change. American Journal of Psychotherapy, 65(4), 337-354.

Viederman, M. (2021). The internalization of a representation of the therapist as an element in psychotherapeutic gain. Psychiatry: Interpersonal \& Biological Processes, 84(1), 46-56.

Winnicott, D. (1965). Maturational processes and the facilitating environment: Studies in the theory of emotional development. London, UK: Hogarth Press.

Winnicott, D. W. (1971). Playing and realty. London, UK: Tavistock Publications. 